\title{
Alfabetização: desafios atuais e novas abordagens
}

\author{
Alfabetización: retos actuales y nuevos abordajes
}

\section{Literacy: current challenges and new approaches}

\author{
Cláudia PRIOSTE ${ }^{1}$ \\ Francisco José Carvalho MAZZEU² \\ Eliza Maria BARBOSA ${ }^{3}$
}

RESUMO: Este texto tem como objetivo apresentar o número especial da Revista Ibero-Americana de Estudos em Educação que traz como tema a Alfabetização, abordada sob uma multiplicidade de aspectos, dimensões e enfoques teóricometodológicos. Agrupando os artigos em função do seu objeto, procuramos indicar ligações que estimulem o debate entre os autores e a identificação de convergências e divergências, convidando para um aprofundamento de temas e para a busca de superação dos desafios apontados. A riqueza de abordagens e análises representada por autores de diversas linhas teóricas e de instituições das cinco regiões do Brasil e do exterior traz um panorama instigante que poderá subsidiar pesquisas e ações futuras no campo da alfabetização.

PALAVRAS-CHAVE: Alfabetização. Políticas públicas. Fracasso escolar. Formação de alfabetizadores. Métodos de alfabetização.

RESUMEN: Este texto tiene el objetivo de presentar el número especial de la Revista Ibero-Americana de Estudos em Educação que trae el tema de la Alfabetización, abordado bajo una multiplicidad de aspectos, dimensiones y enfoques teóricometodológicos. Al reunir los artículos en función de su objeto, buscamos indicar relaciones que estimulen el debate entre los autores y la identificación de convergencias y divergencias, invitando para una profundización de temas y para la búsqueda de superación de los retos apuntados. La riqueza de abordajes y análisis representada por autores de diversas líneas teóricas y de instituciones de las cinco regiones de Brasil y del extranjero muestra un panorama instigador que podrá fundamentar investigaciones y acciones futuras en el campo de la alfabetización.

PALABRAS CLAVE: Alfabetización. Políticas públicas. Fracaso escolar. Formación de alfabetizadores. Métodos de alfabetización.

1 Departamento de Psicologia da Educação. Faculdade de Ciências e Letras - FCLAr/UNESP, Araraquara, Brasil. E-mail: claudiaprioeste@fclar.unesp.br.

${ }^{2}$ Departamento de Didática. Faculdade de Ciências e Letras - FCLAr/UNESP, Araraquara, Brasil. Email: fmazzeu@gmail.com.

3 Departamento de Psicologia da Educação. Faculdade de Ciências e Letras - FCLAr/UNESP, Araraquara, Brasil. E-mail: eliza@fclar.unesp.br. 
ABSTRACT: The purpose of this text is to present the special issue of the Ibero American Journal of Education Studies that focuses the Literacy as a theme, addressed under a multiplicity of aspects, dimensions and theoretical-methodological approaches. By grouping the articles according to their object, we try to indicate links between it which stimulate authors' debate and the identification of convergences and divergences, inviting to a deepening themes and to search for overcoming the mentioned challenges. The richness of approaches and analyzes represented by authors from diverse theoretical lines and institutional affiliation from all regions of Brazil and abroad brings an instigating panorama that could serve as reference for future research and actions in the field of Literacy.

KEYWORDS: Literacy. Public policies. School failure. Literacy training. Literacy methods.

\section{Introdução}

A Revista Ibero-Americana de Estudos em Educação (RIEED) convidou um grupo de docentes da Faculdade de Ciências e Letras da Unesp - Campus de Araraquara para organizarem este número temático da revista, focado no tema "Alfabetização: desafios atuais e novas abordagens", tendo como objetivo apresentar um panorama amplo e diversificado da produção científica nesse campo. A alfabetização, embora seja um assunto que tem merecido atenção e gerado vários debates e polêmicas, constitui uma área temática que tem ainda apresentado dilemas e impasses, desafiando os pesquisadores a buscar novos conhecimentos, que fundamentem propostas, práticas e políticas públicas inovadoras. Entre os problemas que podem ser apontados estão: a definição do papel da Educação Infantil no processo de alfabetização da criança, as dificuldades para assegurar a alfabetização no tempo devido para os alunos do ensino fundamental, as problemáticas psicológicas e socioculturais envolvidas nesse processo e o persistente problema do analfabetismo entre adolescentes e adultos. Ao mesmo tempo em que exigem investigações mais aprofundadas, esses problemas demandam avanços nas abordagens teóricas e metodológicas, que analisam criticamente esse fenômeno à luz das suas relações com a prática social.

Para assegurar a necessária diversidade teórica e institucional, foi lançada uma chamada pública de artigos, convidando autores a submeterem suas produções acadêmicas. O resultado foi bastante significativo. Os artigos recebidos passaram por uma avaliação obedecendo aos critérios da revista e à relevância para a proposta do dossiê, sendo selecionados 18 textos para serem incluídos neste número. Os autores são 
professores doutores e mestres vinculados a universidades das cinco regiões do país e do exterior e as produções atingiram plenamente o objetivo de oferecer aos leitores um panorama da produção científica atual, seus avanços e desafios, bem como apontar temas, questões e caminhos para investigações futuras.

O primeiro texto do número especial, intitulado: “Órfãos do construtivismo" situa o quadro atual da área, do ponto de vista de seus fundamentos teóricos, apontando a condição hegemônica assumida pelo construtivismo como orientador de práticas, pesquisas e políticas públicas. Essa hegemonia vem sendo objeto de crescente questionamento, embora novos paradigmas e concepções ainda não tenham se firmado claramente, deixando "órfãos" muitos professores alfabetizadores. Esse debate traça um pano de fundo que perpassa as discussões apresentadas nos demais artigos, que refletem, cada um a seu modo, o momento histórico em que o campo de estudos se encontra atualmente.

O presente texto, além de apresentar o número especial, procura indicar algumas das conexões, convergências e divergências entre os artigos, estimulando desde já o diálogo e o debate que certamente essas produções irão provocar. Embora vários dos textos transitem entre diferentes momentos do processo de escolarização e abordem temas de interesse geral no campo da alfabetização, optamos por, didaticamente, agrupar os artigos em função do nível de ensino em que estão focados (Educação Infantil, Ensino Fundamental e Educação de Jovens e Adultos) e de temas em comum.

\section{A alfabetização na Educação Infantil e a questão da representação simbólica}

A discussão sobre os limites e contribuições da Educação Infantil ao processo de Alfabetização foi, em diferentes momentos históricos, objeto de divergências e continuidades. Desde as primeiras formulações a respeito da função do pré-escolar, ainda nos anos de 1970, vislumbra-se a alternância entre uma concepção de guarda, compensatória, com a defesa do período pré-escolar com objetivos próprios, até chegarmos, contemporaneamente a uma perspectiva hegemônica que propõe um completo rompimento entre a Educação Infantil e o Ensino Fundamental, âmbito legalmente responsável por assegurar o processo formal de Alfabetização.

Abramovay e Kramer (1991) em artigo produzido há três décadas, defenderam tratar-se de uma ingenuidade política e ideológica condicionar a solução da carência 
cultural de crianças pobres e os altos índices de repetência no ensino de $1^{\circ}$ grau ao préescolar. Ao mesmo tempo, alertavam para o risco de esvaziamento da função deste último, pois, com objetivos em si mesmo e sem relação com o ensino de $1^{\circ}$ grau, a educação pré-escolar poderia facilmente caracterizar-se por práticas informais, assistemáticas e sem exigência de qualidade. As autoras esclarecem. "Não negamos os objetivos imediatos da pré-escola. Longe estamos de subestimar sua função para o desenvolvimento infantil. No entanto, descaracterizar a relação pré-escola-escola é evitar discutir a qualidade que essa pré-escola deve ter". (ABRAMOVAY; KRAMER, 1991, p.33).

Buscava-se um consenso quanto a função da educação pré-escolar que não desconsiderasse a especificidade e necessidades próprias das crianças menores de sete anos, sem entretanto, condená-las a alguns anos de escolarização cujas ações não ultrapassavam o âmbito das experiências informais ou, ao contrário, antecipasse toda a carga de atividades características da alfabetização. Nesse mesmo texto, Abramovay e Kramer (1991, p.36) indicam à época “[...] algumas diretrizes práticas que podem servir de alternativa para a concretização da função pedagógica na pré-escola", entre elas, a função de favorecer o processo de alfabetização, mesmo reconhecendo tratar-se de uma posição polêmica.

No esforço de tentar minimizar tal polêmica, defender uma pré-escola com função pedagógica e dirigida também a favorecer a alfabetização das crianças, as autoras esclarecem que o primeiro passo a ser dado é compreender o processo de alfabetização num sentido mais abrangente. Afirmam que alfabetizar não se restringe ao momento de aplicação de rituais de escrita, leitura e operações matemáticas, mas iniciase quando as crianças se expressam, identificam objetos, "leem" figuras, desenhos, quando suas experiências informais são ampliadas com atividades produzidas na préescola, que teria como objetivo garantir gradativamente às crianças "[ [...] novas formas de expressão e reconhecimento-representação de seu mundo". (ABRAMOVAY; KRAMER, 1991, p.37). 
Mas as formas de representação e expressão vão se diversificando, aos poucos, e se complexificando: de início são motoras e sensoriais (aparecem basicamente como ação); em seguida, simbólicas (aparecem como imitação, dramatização, construção, modelagem, reconhecimento de figuras e símbolos, desenho, linguagem); posteriormente são codificadas (aparecem como leitura e escrita). Compreender que a alfabetização tem esse caráter dinâmico de construção significa, então compreender que os mecanismos da leitura e da escrita se constituem numa parte integrante do processo, que é beneficiada pelas etapas anteriores. (ABRAMOVAY; KRAMER, 1991, p.37).

O pioneirismo e a atualidade da perspectiva dessas autoras encontram-se representados nesta coletânea pelos textos que têm as práticas na Educação Infantil como objeto, relacionando-o com a Alfabetização. O primeiro artigo, que se intitula: "O

\section{desenho infantil de crianças de três anos e sua articulação com os rudimentos da} escrita" apresenta e discute, sob as bases teóricas da Psicologia Histórico-Cultural e da Pedagogia Histórico-Crítica, a proposição de uma sequência pedagógica desenvolvida com crianças de três anos de idade em uma escola pública do município de Araraquara/SP, cuja finalidade era o aperfeiçoamento do desenho do esquema corporal. As autoras defendem que, embora a Educação Infantil não tenha como função precípua a consolidação do processo de alfabetização, pode oferecer-lhe uma contribuição original à medida que esse processo seja concebido como resultado de aprendizagens que articulam os gestos, a linguagem oral, o desenho e a escrita, numa trajetória de construção coletiva e cultural. Sob a evidência teórica da capacidade exclusivamente humana e não-natural de representar a realidade por diferentes ações, o texto sustenta que a escola na sociedade contemporânea tornou-se a forma predominante de educação das novas gerações e, por isso mesmo, o lócus do seu processo de humanização. São apresentadas as ações pedagógicas que constituem a sequência didática, sendo que a análise dos avanços percebidos nos desenhos das crianças indica sua importância como forma de objetivação da realidade, fenômeno que ocorrerá novamente mais tarde por meio da escrita.

Imbuído do mesmo propósito de defender como ocorre o processo de apropriação da linguagem escrita por crianças de Educação Infantil e orientado pelo mesmo referencial teórico do primeiro artigo, a Psicologia Histórico-Cultural, apresenta-se o texto intitulado: “Considerações sobre o processo de apropriação da linguagem escrita na educação infantil”. Os autores anunciam a articulação funcional entre o desenvolvimento do pensamento e da linguagem como a base para a formação 
das funções psicológicas superiores, demonstrando que, pela linguagem, as crianças ampliam seu domínio sobre os signos e suas relações com os significados culturais, ao mesmo tempo em que o pensamento converte-se em lógico-abstrato. $\mathrm{O}$ texto indica aos professores da Educação Infantil que a observação do desenvolvimento do signo por meio das relações entre o gesto e as garatujas (expressas nos desenhos) e mais tarde, os gestos e as brincadeiras, pode constituir-se como uma importante fonte de identificação de como está ocorrendo a trajetória de desenvolvimento que culminará no domínio da linguagem escrita.

O terceiro texto desse bloco: "Brincar com a linguagem: educação infantil "rima" com alfabetização?" propõe uma reflexão sobre as contribuições da Educação Infantil à Alfabetização através de situações educativas de reflexão sobre a dimensão sonora da língua, devendo ocorrer em contextos lúdicos e de brincadeiras com a linguagem. O texto argumenta que polemizar entre a defesa de uma Educação Infantil com importância em si mesma ou de caráter preparatório para o Ensino Fundamental não produz grandes avanços. No lugar de tal polêmica, a autora afirma que o objetivo principal do trabalho é reconhecer que as contribuições da Educação Infantil, de modo especial por meio de práticas na dimensão sociodiscursiva da aprendizagem da leitura e da escrita, tributam tanto em favor da inserção das crianças menores de seis anos na cultura e na linguagem escrita, quanto no domínio progressivo da alfabetização no Ensino Fundamental. Conclui defendendo que as brincadeiras com a dimensão sonora da língua e a tradição de textos orais na Educação Infantil, podem viabilizar consensos em torno do direito fundamental das crianças de serem alfabetizadas e letradas, respeitando o modo de aprender das crianças pequenas, mas ao mesmo tempo ampliando de modo progressivo e contínuo as aprendizagens sobre a linguagem escrita.

Fechando os textos que vinculam a Alfabetização e a Educação Infantil, temos o trabalho sob o título: "Os caminhos escolhidos pela educação infantil para alfabetizar matematicamente as crianças de 04 e 05 anos". Trata-se dos resultados de uma pesquisa que teve como objetivo identificar como as crianças de 04 e 05 anos consolidam seus conhecimentos numéricos de recitar, contar e escrever números, tomando como objeto para análise, as orientações presentes no Referencial Curricular Nacional para a Educação Infantil e as metodologias utilizadas pela professora de uma escola da rede pública de ensino. O referencial Psicogenético constitui a base para a fundamentação teórica e as análises dos dados obtidos por meio de entrevista com a professora, observações em sala de aula e verificação da sistematização feita pelas 
crianças em seus cadernos de registro. $\mathrm{O}$ resultado indica que é necessário buscar tanto uma atualização do referencial curricular nacional quanto das metodologias usadas pela professora, incluindo em ambos, as tecnologias usadas pelas crianças como jogos, computadores, calculadoras, etc. O texto substancia a defesa de práticas de ensino de matemática que, ao ensinar a recitar, contar/quantificar e escrever números, valorizem as situações do dia-a-dia, de rotina e jogos em que essas funções do número se fazem presentes, pois essas seriam, de acordo com o autor, uma forma de garantir uma aprendizagem mais significativa pelas crianças.

\section{A alfabetização no Ensino Fundamental e a questão do fracasso escolar}

Os anos iniciais do ensino fundamental são, em certa medida, determinantes na relação que a criança manterá com a escola nos anos subsequentes, podendo favorecer ou obstruir seu percurso. Nesse sentido, uma alfabetização bem consolidada é a base mínima para que o aluno possa se apropriar de uma parte do legado histórico e cultural que o antecede, possibilitando não somente a ampliação de seu universo de conhecimentos, como também lhe abrindo perspectivas para que no futuro possa se posicionar criticamente na sociedade. Contudo, a despeito das inúmeras políticas públicas implementadas nas últimas décadas visando melhorar as performances das crianças na leitura e escrita, o Brasil ainda continua com dificuldades em avançar.

As problemáticas no processo de alfabetização nos anos iniciais do Ensino Fundamental têm ligação intrínseca ao fracasso escolar como um todo, e que no Brasil é crônico, cruel e desafiador. Nos anos de 1980, Patto (2000) realizou uma ampla pesquisa abordando tanto as raízes históricas das explicações sobre o fracasso escolar, quanto uma análise sobre o cotidiano das instituições educativas brasileiras e seus funcionamentos excludentes. Identificou a predominância de explicações pautadas em teorias raciais, em abordagens biológicas e psicológicas simplistas, somadas à perspectiva da carência cultural. Constatou a tendência de se atribuir exclusivamente à criança e aos seus familiares as causas do fracasso escolar, ignorando as desigualdades historicamente engendradas.

É importante lembrar que naquele período um dos principais indicadores do fracasso escolar era a repetência. Segundo Silva e Davis (1993), as taxas de repetência no Brasil eram as mais altas e também as mais estáveis em relação aos demais países da 
América do Sul: em 1971 era de 55,8\% e em 1984 era de 54,3\%, atingindo principalmente as crianças mais pobres. Nesse contexto e, em meio ao debate de maior democratização na sociedade brasileira, foram lançadas as concepções de Ciclos Básicos de Alfabetização visando diminuir os índices de reprovação e melhorar a qualidade do ensino. Entretanto, as implantações dos ciclos, inicialmente nos estados de São Paulo, em 1983, e Minas Gerais, em 1985, foram alvos de inúmeras críticas, entre elas as contrariedades dos professores com relação à forma autoritária com que foram implantados, a ausência de apoio suplementar às crianças com dificuldades, bem como problemas referentes à estrutura escolar e alta rotatividade docente prejudicando a execução do programa em sua concepção original.

Diversas políticas educacionais foram implementadas a partir dos anos de 1990, porém com poucos resultados efetivos na melhoria da qualidade do ensino. Em 2005, um relatório produzido pelo Instituto Nacional de Estudos e Pesquisas Educacionais Anísio Teixeira (INEP) sobre avaliação da Educação Básica destacava a posição do Brasil no Índice de Desenvolvimento do programa de monitoramento global "Educação para Todos" da UNESCO. Esse índice se baseava nas seguintes metas: educação primária universal, alfabetização de adultos, qualidade e paridade de gênero. Na primeira meta, o Brasil ocupava o $32^{\circ}$ lugar, na segunda, o $67^{\circ}$ lugar, porém no que tange à qualidade, o país ocupava a $87^{\mathrm{a}}$ posição, isto é, obteve a pior performance. Nesse mesmo documento, os autores evidenciam os avanços em relação ao acesso e ao fluxo, com significativa melhora na taxa de frequência escolar das crianças com idade entre 7 e 14 anos, que em 1980 era de 80,9\%, em 2000 passou a ser de 96,4\% e em 2002 alcançou o índice de 96,9\% (ARAÚJO; LUZIO, 2005). No entanto, a despeito de maior acesso e melhoria no fluxo, os problemas com relação à proficiência em leitura e em matemática perduravam:

De uma forma geral, os resultados do Saeb em 2003 mostram que $55 \%$ das crianças da $4^{\mathrm{a}}$ série estavam concentradas nos estágios muito crítico e crítico de proficiência em Leitura; em Matemática, eram 52\% dos alunos. Em Leitura, isso indica incapacidade de compreender plenamente textos simples, curtos e de gêneros variados. Em Matemática, os níveis muito crítico e crítico reúnem estudantes que não conseguem solucionar problemas simples, envolvendo soma ou subtração de números naturais, formulados a partir de situações do cotidiano. (ARAÚJO; LUZIO, 2005, p.37). 
Percebe-se que apesar dos avanços na universalização da educação básica, o Brasil continuou adotando funcionamentos escolares que resultavam não somente em alunos, mas também em professores que se sentiam fracassados. De acordo com Souza (2010) a proibição da repetência somada às políticas de inclusão de crianças com todos os tipos de deficiência nas salas de aula regulares sem suportes adequados, contribuiu para aumentar as dificuldades docentes na rede pública de ensino. Um cotidiano escolar marcado por improvisos e por alta rotatividade da equipe é um "[...] mecanismo que ensina o desapego à instituição, às pessoas e ao sentido do trabalho." (SOUZA, 2010, p.249). Outro fator importante destacado pela autora refere-se à baixa remuneração e a necessidade de acúmulo de turnos por parte dos professores, gerando grande desgaste físico e mental.

A progressiva desqualificação dos saberes profissionais, bem como o sentimento de solidão no contexto escolar contribuiu para intensificar o sofrimento dos professores. Suas incapacidades ganharam destaques, ao mesmo tempo em que inúmeras capacitações e cursos foram criados, sobretudo a partir dos anos de 1990, com o intuito suprir a suposta incompetência (SOUZA, 2010). As explicações do fracasso escolar no Brasil continuaram enfatizando as debilidades biológicas, psicológicas e socioculturais das crianças e seus familiares, acrescentando também as incompetências docentes sem contextualizar as dimensões políticas, ou seja, sem levar em conta os aspectos ideológicos das desigualdades socialmente engendradas (ANGELUCCI et al., 2004). Além disso, os professores passaram a ser acusados de resistência às mudanças advindas tanto das políticas públicas supostamente inclusivas, quanto das concepções construtivistas, aparentemente inovadoras, e que se tornaram hegemônicas nas últimas três décadas. Assim, muitos professores alfabetizadores experientes se tornaram, de certo modo, clandestinos, necessitando esconder suas práticas, não obtendo reconhecimento de suas experiências profissionais, o que culminou em inúmeras frustrações e desencanto com a profissão.

Diante desses impasses, adversidades e desafios, torna-se importante compartilhar alguns estudos que tratam dos anos iniciais do Ensino Fundamental e do fracasso escolar, destacando experiências e reflexões sobre essa fase. O primeiro deles, intitulado "O desafio do ensino da leitura no contexto contemporâneo" apresenta os resultados parciais de uma interessante pesquisa longitudinal, realizada entre os anos de 2011 e 2014 na escola de aplicação da USP, cuja proposta foi reunir elementos para um programa de ensino com ênfase na oralidade e nas tradições culturais brasileiras, 
levando em conta a diversidade e a heterogeneidade dos grupos na perspectiva dos ciclos.

O segundo artigo: “Transposição didática em alfabetização: uma aproximação a partir de cadernos escolares" toma os cadernos escolares de Língua Portuguesa como objeto de estudo. A pesquisa foi realizada com alunos do Ensino Fundamental I, em três escolas públicas, duas da cidade do Rio de Janeiro e uma de Belo Horizonte, destacando a importância dos cadernos não somente como suportes da escrita, mas também como indicadores das práticas de alfabetização.

O terceiro artigo: “A alfabetização no ensino fundamental de nove anos no contexto das políticas educacionais: alguns desafios para reflexão" analisa os dados do Censo Escolar e os resultados da Avaliação Nacional de Alfabetização de 2014 destacando o grande número de crianças que chegam ao $3^{\circ}$. ano do Ensino Fundamental sem aprender a ler e a escrever. As autoras também discutem os aspectos subjacentes às políticas de universalização da educação básica, sobretudo em seu viés neoliberal, onde as escolas públicas permanecem em situação precária e com um currículo reducionista voltado basicamente aos interesses de mercado.

O quarto artigo "Estratégias de leitura e mediação do professor: o desafio de formar leitores no terceiro do ensino fundamental" faz uma discussão das estratégias de leitura e apresenta dados de uma pesquisa qualitativa de caráter etnográfico na qual as autoras destacam o papel mediador da professora nas atividades de leitura das crianças, revelando as estratégias utilizadas pelos alunos e as dificuldades decorrentes da ausência de uma mediação mais adequada.

O quinto artigo: "Fracasso escolar e dificuldades na alfabetização: relato de experiência de atendimento psicológico e novas intervenções" traz um exemplo dos entraves no processo de alfabetização e a tendência de psicopatologizar os problemas escolares. $\mathrm{O}$ artigo relata as experiências de atendimento às queixas escolares em uma Unidade Básica de Saúde (UBS), destacando o caso de uma criança de 11 anos, estudante do $4^{\circ}$ ano, que não estava alfabetizada e foi encaminhada ao serviço de psicologia sem nunca ter recebido um apoio pedagógico na própria escola. A partir do desdobramento bem sucedido desse caso, discute-se a perpetuação de estigmas às famílias pobres, a falta de autonomia docente no processo de alfabetização, bem como o papel do psicólogo na mediação entre família e escola, propondo novas perspectivas de diagnóstico e de intervenção. 
Por fim, o sexto artigo relacionado ao Ensino Fundamental e fracasso escolar aponta algumas críticas, esperanças e caminhos. Apresentando um título provocativo: “Alfabetização: por que a criança não aprende a ler e a escrever?" as autoras analisam os materiais e as propostas do Pacto Nacional para Alfabetização na Idade Certa (PNAIC) revelando suas fragilidades e incoerências. Além disso, descrevem uma pesquisa realizada no município de Presidente Prudente onde foram empregadas metodologias de ensino sistemático nos primeiros anos de Ensino Fundamental alcançando-se significativos resultados na aquisição da leitura e escrita pelas crianças, como também a formação de valores de cordialidade. Concluem que a falta de clareza e objetividade no ensino têm prejudicado o processo de alfabetização.

\section{A alfabetização na Educação de Jovens e Adultos, as políticas públicas de} formação de alfabetizadores e a questão dos métodos

$\mathrm{O}$ analfabetismo entre jovens e, sobretudo, entre adultos no Brasil desafia o poder público e a sociedade em geral. Apesar dos vários programas voltados para enfrentar esse problema, promovidos por diferentes esferas de governo e organizações da sociedade civil, o número de analfabetos no país diminui em ritmo lento, frustrando expectativas e metas. A título de exemplo, pode-se perceber que desde a Constituição Federal de 1988 têm sido lançadas iniciativas com o propósito de "erradicar" o analfabetismo absoluto, geralmente em um período de 10 anos. O Plano Nacional de Educação - PNE 2001-2011 estabeleceu esse objetivo, mas não obteve sucesso na sua realização. O atual PNE (2014-2024) consignou na sua Meta 9 que o analfabetismo absoluto seria eliminado até o final desse período (BRASIL, 2014). Tudo indica que essa meta, assim como ocorreu no plano anterior, não será cumprida.

Como explicar esse fracasso? De um lado, aspectos teóricos e metodológicos têm minado muitos dos esforços dos professores e das escolas de Educação Infantil e Ensino Fundamental para assegurar uma alfabetização efetiva para todas as crianças, conforme apontam vários textos deste número. De outro lado, as políticas públicas voltadas para a alfabetização, tanto de crianças como de jovens e adultos, não têm produzido as mudanças necessárias e oferecido as condições mínimas (inclusive no que se refere a investimentos em infraestrutura, qualificação e remuneração de professores, etc.) para que ocorra um avanço mais rápido e consistente na direção de um sistema de ensino que ofereça uma alfabetização de qualidade para todos. A descontinuidade e 
desarticulação dos programas, aliada às suas inconsistências e fragilidades teóricometodológicas ou operacionais, conduz a um quadro de desalento dos profissionais da educação e à persistência dos problemas crônicos que sustentam a desigualdade na oferta de ensino, refletindo e reforçando as desigualdades sociais, regionais e econômicas.

Esses aspectos se manifestam na concepção e na execução de políticas públicas como o Pacto pela Alfabetização na Idade Certa - PNAIC que é o objeto (de forma direta ou indireta) de quatro artigos deste número. Esses artigos demonstram, com base em pesquisas, as potencialidades e as dificuldades colocadas para a formação de professores alfabetizadores no contexto dessa política.

No texto: "O Pacto Nacional pela Alfabetização na Idade Certa e a responsabilização (accountability) do professor alfabetizador" a autora explicita uma contradição desse programa: ao mesmo tempo em que se responsabiliza o professor alfabetizador pelos resultados a serem alcançados, não se oferece a esse profissional um papel de protagonista e de sujeito participante nas principais decisões referentes à sua própria formação. A lógica de formar multiplicadores que irão "repassar" os conteúdos dos cursos de formação, sem que sejam alteradas as condições efetivas de trabalho e atuação dos professores alfabetizadores, inclusive a sua relação com a universidade, pode resultar em um processo que, na prática, acaba culpando o professor pelo eventual fracasso da política pública.

Essas dificuldades do PNAIC, porém, não eliminam sua importância como ação formativa, aspecto que é ressaltado no artigo: "Formação continuada de professores alfabetizadores: as (re)significações docentes com base nas ações do PNAIC em Santa Catarina”. As autoras relatam uma experiência no âmbito desse programa a partir de relatórios de visitas técnicas. Se, por um lado, as análises evidenciam os impactos da formação oferecida na prática dos professores alfabetizadores, com a incorporação de procedimentos como o uso mais intenso de textos literários e de jogos, por outro lado os dados chamam a atenção para a necessidade de discutir e questionar os fundamentos dessas práticas, articuladas em torno da ideia de uma "alfabetização na perspectiva do letramento".

Essa discussão dos fundamentos teóricos da formação de professores alfabetizadores é abordada no artigo: "Desafios da formação de professores alfabetizadores: em busca da apropriação da linguagem escrita como desenvolvimento humano" no qual as autoras buscam explicitar elementos da 
abordagem Histórico-Cultural que deveriam estar sendo considerados nas ações formativas com esses professores. Rejeitando uma formação que atribua exclusivamente ao professor a responsabilidade pelo resultado de ações que são de natureza histórica e social e que seja focada somente nos aspectos práticos e técnicos do trabalho do professor, as autoras defendem a busca de unidade entre teoria e prática, a partir de uma concepção crítica desses processos formativos e de uma perspectiva humanizadora da linguagem escrita e de seu significado na formação do aluno.

O conjunto de quatro artigos que fecha o número especial aponta para uma questão que vem sendo objeto de intensos e apaixonados debates: a adoção de métodos para conduzir o processo de alfabetização. O primeiro texto, fruto de uma colaboração de pesquisadores da Unesp com uma pesquisadora da Universidade de Havana, em Cuba, traz uma reflexão sob o título: "El processo de alfabetización de jóvenes $\mathbf{y}$ adultos desde el enfoque Histórico-cultural y el método cubano 'yo si puedo"”. Como se anuncia no título, os autores discutem os fundamentos teóricos de um método produzido em Cuba e amplamente difundido em quase 30 países, em especial na América Latina, embora ainda pouco estudado no Brasil. Esse método resgata procedimentos oriundos de práticas tradicionais de alfabetização, combinando com inovações vinculadas ao enfoque histórico-cultural e a contribuições de Paulo Freire. Dessa forma, a questão do ecletismo metodológico é apontada como um aspecto que parece estar presente nesse método e merece estudos futuros.

No artigo: "Método de alfabetização fonovisuarticulatório na EJA: estudo de caso" as autoras apresentam uma experiência baseada na utilização de um método derivado do método fônico, que se caracteriza pela apresentação dos movimentos do aparelho fonador como suporte para facilitar a identificação dos fonemas da língua e sua associação com os respectivos grafemas. Ao mesmo tempo, as autoras não descartam a adoção de classificações como as de Emília Ferreiro para a identificação da etapa em que o aluno se encontra. $\mathrm{O}$ artigo é representativo do esforço de vários alfabetizadores e pesquisadores para retomar métodos tradicionais como o método fônico, procurando fundamentá-lo em novas bases científicas e empíricas.

Indo em direção semelhante, o artigo: "Aprender a escrever: contribuição das habilidades de consciência fonêmica, nomeação seriada rápida e memória de trabalho" embora não tenha o método como foco principal, apresenta os resultados de uma pesquisa sobre três habilidades envolvidas na leitura e na escrita: a consciência fonêmica, a habilidade de manter a informação fonológica na memória de curto prazo 
(memória de trabalho) e a habilidade de acessar e recuperar com rapidez a informação no léxico mental (RAN). Utilizando o controle de variáveis como metodologia de pesquisa, a autora aponta a importância do desenvolvimento sistemático dessas habilidades, destacando a mudança no papel de cada uma e em sua importância ao longo do processo de alfabetização, bem como as suas relações com o sistema ortográfico da língua portuguesa. Estudos como esse têm sido utilizados como referência para a defesa da adoção de um trabalho sistemático para desenvolver, na alfabetização, determinadas habilidades cognitivas como a consciência fonêmica/fonológica. Isso não implica, necessariamente, a adoção de métodos centrados no reconhecimento de fonemas, mas aponta para a necessidade de recuperar o ensino sistemático das relações entre fonemas e letras.

Defendendo a necessidade desse ensino sistemático, mas seguindo um caminho teórico distinto, os autores do texto: "Notas introdutórias para um método HistóricoCrítico de alfabetização" apontam para a necessidade desenvolver orientações mais específicas para a alfabetização a partir dos pressupostos dessa abordagem pedagógica e procuram indicar elementos para essa tarefa, sugerindo um esforço para superar dialeticamente os métodos atualmente em uso e promover uma prática mais intencional. Para tanto, indicam a necessidade de partir dos objetivos e conteúdos da alfabetização e de uma concepção de linguagem escrita coerente com os fundamentos da Pedagogia Histórico-Crítica para se chegar a procedimentos didáticos que avancem na organização do trabalho do professor alfabetizador. Nesse sentido, defendem que a alfabetização precisa levar em conta a unidade dialética da dimensão semântica e fonética da linguagem e apontam para o uso de palavras como mediadores para o ensino sistemático dos conteúdos específicos dessa etapa da escolarização. Consideram, ainda, que o professor precisar ser revalorizado no seu papel de produtor das suas atividades e instrumentos de ensino, para que possa realmente contribuir na superação dos desafios atuais da sala de aula.

\section{Considerações finais}

Muitos são os desafios que se colocam no campo da alfabetização, nos diversos níveis de ensino, nas políticas públicas e na formação de professores. O número especial que ora apresentamos traz um panorama geral que mostra não apenas a complexidade 
dos problemas a enfrentar, mas a diversidade de abordagens teóricas que fundamentam as investigações e reflexões dos pesquisadores. Se por um lado se avolumam as críticas à abordagem construtivista, cuja hegemonia parece não ter produzido os resultados esperados, por outro lado, não está claramente delineado qual ou quais serão as bases que irão orientar a ação dos professores nos próximos anos. Será a retomada do método fônico ou de outros métodos tradicionais de alfabetização, revisitados e "repaginados" com o suporte da chamada Ciência Cognitiva e da Neurociência? Serão os estudos do interacionismo dialógico e da linguística da enunciação que produzirão novas práticas de alfabetização, sem assumirem um caráter explicitamente metodológico? Será a Pedagogia Histórico-Crítica e seus fundamentos na Psicologia Histórico-Cultural que sustentarão a produção de novos métodos e novas práticas, superando por incorporação os métodos tradicionais e o construtivismo? Ou será uma abordagem eclética, que se propõe a combinar fundamentos e procedimentos de diferentes origens e matrizes teóricas, o caminho mais adequado para avançar na prática de sala de aula?

Embora os editores deste número e cada um dos autores que nele colaboram possuam suas próprias posições e defendam caminhos distintos, com certeza temos em comum a convicção de que o debate acadêmico é fundamental para subsidiar as políticas e as práticas futuras, tendo como pressuposto que uma alfabetização de qualidade para todos e todas é um direito inalienável e precisa ser assegurada pelo poder público. Esperamos que este número especial ajude a promover esse debate.

\section{Agradecimentos}

Agradecemos à Associação Nacional de Pós-Graduação em Educação - Anped e à Associação Brasileira de Alfabetização - Abalf pela preciosa colaboração na divulgação da chamada de artigos para este número da revista.

\section{REFERÊNCIAS}

ABRAMOVAY, M.; KRAMER, S. "O rei está nu”: um debate sobre as funções da préescola. Cadernos Cedes, Campinas, v.1, n.9, p.27-38, 1991. 
ANGELUCCI, C. B. et al. O estado da arte da pesquisa sobre o fracasso escolar (19912002): um estudo introdutório. Educação e Pesquisa, São Paulo, v.30, n.1, p.51-72, jan./abr. 2004.

ARAÚJO, C. H.; LUZIO, N. Avaliação da educação básica: em busca da qualidade e equidade no Brasil. Brasília: INEP, $2005 . \quad$ Disponível em: <http://www.publicacoes.inep.gov.br/portal/download/446>. Acesso em: 20 nov. 2016.

BRASIL. Ministério da Educação. Plano Nacional de Educação 2014-2024 [recurso eletrônico]: Lei $\mathrm{n}^{\circ}$ 13.005, de 25 de junho de 2014, que aprova o Plano Nacional de Educação (PNE) e dá outras providências. Brasília: Câmara dos Deputados, Edições Câmara, 2014. (Série legislação, 125).

PATTO, M. H. S. A produção do fracasso escolar: histórias de submissão e rebeldia. São Paulo: Casa do Psicólogo, 2000.

SILVA, R. N.; DAVIS, C. É proibido repetir. Estudos em Avaliação Educacional, São Paulo, n.7, p.5-44, jan./jun. 1993.

SOUZA, B. P. Funcionamentos escolares e produção do fracasso escolar e sofrimento. In: SOUZA, B. P. (Org.) Orientação à queixa escolar. São Paulo: Casa do Psicólogo, 2010. p.241-278.

\section{Como referenciar este artigo}

PRIOSTE, Cláudia; MAZZEU, Francisco José Carvalho; BARBOSA, Eliza Maria. Alfabetização: desafios atuais e novas abordagens. Revista Ibero-Americana de Estudos em Educação, Araraquara, v. 11, n. esp. 4, p.2251-2266, 2016. Disponível em: <https://dx.doi.org/10.21723/riaee.v11.n.esp4.9189>. E-ISSN: 1982-5587.

Submetido em: outubro/2016

Aprovado em: novembro/2016 